\title{
La especificidad del Estado en América Latina. Apuntes a partir de la obra de René Zavaleta Mercado
}

\author{
The specificity of the State in Latin America. \\ Notes from the work of René Zavaleta Mercado
}

\section{J. Fabian Cabaluz D.*}

\begin{abstract}
Resumen: El trabajo reflexiona en torno a la especificidad del Estado en América Latina a partir de la obra de René Zavaleta Mercado. Para ello, el texto refiere en un primer momento a la pertinencia de su obra; posteriormente reflexiona sobre la cuestión nacional en el marco de formaciones sociales abigarradas; en un tercer apartado, recoge planteamientos teórico-políticos en torno al Estado y su especificidad latinoamericana; y finaliza abordando problemáticas asociadas a la dictadura, la democracia y la autodeterminación de masas.
\end{abstract}

Palabras clave: Cuestión Nacional, Sociedad abigarrada, Forma primordial, Autodeterminación de las masas

\begin{abstract}
The work reflects on the specificity of the State in Latin America from the work of René Zavaleta Mercado. For this, the text refers first to the relevance of his contribution; later it reflects on the national question in the context of disjointed social formations; in a third section, it collects theoretical-political approaches around the State and its Latin American specificity; and it ends by tackling issues associated with dictatorship, democracy and mass self-determination.
\end{abstract}

Keywords: National Question, Variegated society, Primary form, Mass self-determination

Recibido: 23 abril 2017

Aceptado: 9 septiembre 2017 


\section{Una entrada desde el marxismo latinoamericano}

René Zavaleta Mercado (1937 - 1984) se ha configurado como un referente intelectual del marxismo en Bolivia y América Latina ${ }^{1}$. Su producción teórica, fecunda en términos conceptuales, es una suerte de núcleo de buen sentido para el desarrollo del pensamiento social crítico latinoamericano. El universo categorial, conformado por conceptos como el de formación social abigarrada, ecuación social, forma primordial, momento constitutivo, autodeterminación de las masas, entre otros, permite reflexionar a las izquierdas latinoamericanas actuales, desde un marxismo crítico y creativo, sobre problemas políticos asociados al Estado, la cuestión nacional, la dependencia y la compleja relación entre socialismo y democracia.

La producción intelectual de René Zavaleta, ha cobrado vitalidad en las ciencias sociales bolivianas, particularmente por la influencia de su obra en quienes dieron vida desde fines de la década del noventa al Colectivo Comuna. Entre ellos destacan Álvaro García Linera, Luis Tapia, Raúl Prada y Raquel Gutiérrez. Cada uno de los autores, desde sus diferentes trincheras y esferas de acción, han retomado categorías y perspectivas de análisis de raigambre zavaletiana. A modo de ejemplo, podemos señalar que el actual vice-presidente de Bolivia, Alvaro García Linera (2015), referencia de manera permanente conceptos zavaletianos para explicar los procesos políticos impulsados por el Movimiento al Socialismo (MAS) y el Gobierno de Evo Morales. En este sentido ha recogido la categoría de formación social abigarrada, para sustentar teórica y políticamente la construcción del Estado Plurinacional de Bolivia, y a su vez, para dotar de legitimidad a la creación de espacios de democracia comunitaria y directa en el actual proceso de construcción del socialismo en Bolivia.

Retomando aspectos asociados a la obra de René Zavaleta, podemos agregar que ésta no sólo se centró en la realidad boliviana, sino que, a partir de la experiencia del exilio, vivida desde el año 1964 y que lo llevó a radicarse en Uruguay, Inglaterra, Chile y México, desarrolló un cúmulo de textos y reflexiones en torno a los procesos históricos latinoamericanos. Como marxista, a lo largo de su producción teórico-política, incorporó a los clásicos (K. Marx, F. Engels, V. Lenin, G. Lucaks, L. Trostsky, A. Gramsci y J.C. Mariategui) y también a sus contemporáneos (L. Althusser, N. Poulantzas, R. Miliband y E.P. Thompson). La riqueza de sus planteamientos se expresa en escritos que intentan

\footnotetext{
* Chileno. Docente e investigador de la Escuela de Pedagogía en Historia y Ciencias Sociales de la Universidad Academia de Humanismo Cristiano. Estudiante Doctorado en Estudios Latinoamericanos, Universidad de Chile. Becario CONICYT Doctorado Nacional, 2016, folio N ${ }^{\circ} 21160786$. fabiancabaluz@gmail.com

${ }^{1}$ En términos editoriales, ha sido relevante la publicación en Bolivia el año 2010 de sus obras completas por parte de Plural Editores. Además, a nivel latinoamericano, se ha publicado la antología de René Zavaleta realizada por Luis Tapia y publicada por CLACSO, en el año 2009, bajo el título La Autodeterminación de las Masas. Y a dicho texto, se puede agregar una compilación de textos publicada recientemente en Chile y Argentina por Guiller, Diego y Ouviña, Hernán (comp.). René Zavaleta Mercado. Pensamiento crítico latinoamericano y marxismo abigarrado. Santiago de Chile. Editorial Quimantú, 2016.
} 
traducir las categorías de Marx y del marxismo en función de nuestras realidades específicas. Al decir de Luis Tapia, el sociólogo y periodista boliviano elaboró una recuperación selectiva de la producción teórica de Marx, de acuerdo a los grandes problemas de Bolivia y América Latina².

La vigencia y potencialidad de su arquitectura conceptual radica en una posición antidogmática de comprensión del marxismo, la cual se opuso permanentemente a explicaciones cerradas y escolásticas de la realidad. Además, su obra fue heterodoxa con respecto a los planteamientos de la URSS, todo lo cual nos permite asociarla al desarrollo de un marxismo latinoamericano original, entrelazado a la producción teórica y política del peruano José Carlos Mariátegui. Así lo expresa uno de los principales estudiosos de su obra: "Lo que tenemos, entonces, es un proceso de apropiación teórica de ideas marxistas, de las categorías centrales para pensar la configuración del mundo social y del mundo moderno en particular, que se realiza para trabajar y desarrollar explicaciones de realidades nacionales, de configuraciones sociales específicas" ${ }^{3}$.

Retomando lo anterior, nos parece que la producción teórico-política de Zavaleta avanzó en procesos de nacionalización de la teoría crítica marxista, preocupándose permanentemente por lo histórico concreto y la especificidad de lo local. El énfasis se encuentra en la lógica del lugar, por sobre la lógica del mundo, es decir, en la producción de conocimiento local y situado. Planteado en otros términos, la socióloga mexicana Elvira Concheiro ha señalado que René Zavaleta recogió una contribución metodológica y política de Lenin: "La construcción de una propuesta teórico-política de gran alcance a partir del análisis concreto de las situaciones concretas o específicas"4. Así entonces, el punto de partida de Zavaleta será siempre la realidad histórica precisa y concreta.

Otro aspecto que no podemos omitir con respecto a la producción teórico-política de René Zavaleta, es su capacidad de articular trabajo intelectual y militancia. En este sentido, sus escritos emanan de la praxis, de la articulación coherente y consecuente con un proyecto de clase, popular, emancipatorio. Esto se expresó durante su itinerario vital, en la adscripción al Movimiento Nacional Revolucionario, MNR; en la proximidad con el proceso chileno de la Unidad Popular, con la experiencia boliviana de la Asamblea Popular de 1971; en su

\footnotetext{
2 Según Luis Tapia, René Zavaleta se posicionó desde el marxismo reconociendo teorías generales y elementos homogeneizadores y regulares del capitalismo, pero al mismo tiempo, esto lo articuló con investigación histórica en torno a lo nacional-popular en Bolivia. Así, en la producción teórica y política de Zavaleta, las teorías generales del marxismo fueron tensionadas y llevadas a sus límites desde el conocimiento histórico. Para profundizar en ello ver: Tapia, Luis. "Prólogo". En La Autodeterminación de las masas. René Zavaleta, Antología. Bogotá, Siglo del Hombre Editores y CLACSO, 2009. Y Tapia, Luis. "Consideraciones sobre el trabajo teórico de Zavaleta a partir de la obra de Marx” En René Zavaleta Mercado. Pensamiento crítico y marxismo abigarrado. Santiago de Chile, Editorial Quimantú, 2016.

3 Tapia, Luis. De la forma primordial a América Latina como horizonte epistemológico. La Paz, Editorial CIDES - UMSA, 2013, p. 92.

${ }^{4}$ Concheiro, Elvira. "El análisis concreto de situaciones concretas: Lenin en la obra de René Zavaleta". En René Zavaleta Mercado. Pensamiento crítico y marxismo abigarrado. Santiago de Chile, Editorial Quimantú, 2016, p. 29.
} 
participación en el nacimiento del Movimiento de Izquierda Revolucionaria de Bolivia (MIR); en su afiliación al Partido Comunista Boliviano; y en la fundación de la Facultad Latinoamericana de Ciencias Sociales, FLACSO, espacio que dirigió entre 1976 y 1980. Su trayectoria política permite sostener, a varios de sus intérpretes, que fue un intelectual orgánico, un intelectual militante del nacionalismo revolucionario y el marxismo, un teórico de la praxis.

El presente trabajo pretende reflexionar, de manera introductoria, en torno a la especificidad del Estado en América Latina a partir de algunos ensayos de la obra del marxista boliviano. Para ello retomaremos seis escritos elaborados por René Zavaleta Mercado entre 1979 y 1983, es decir en los últimos años de su producción teórica. Los materiales que utilizaremos en nuestro análisis serán: "Notas sobre fascismo, dictadura y coyuntura de disolución" (1979); "Notas sobre la cuestión nacional en América Latina" (1981); "Cuatro conceptos de la Democracia" (1981); "Problemas de la determinación dependiente y la forma primordial" (1983); "Ni piedra filosofal ni Summa Feliz" (1983); y "El Estado en América Latina" (1983).

El escrito lo organizaremos de la siguiente manera: En un primer momento nos aproximaremos a los textos de René Zavaleta Mercado en torno a la cuestión nacional en el marco de formaciones sociales abigarradas; en un segundo apartado, nos detendremos en reflexiones teórico-políticas en torno al Estado y su especificidad en América Latina; y finalizaremos el trabajo con un tercer momento en que, desde una perspectiva más concreta, se abordarán reflexiones en torno a las dictaduras latinoamericanas, la democracia y la autodeterminación de las masas.

\section{Apuntes en torno a lo nacional (en sociedades abigarradas)}

En el ensayo titulado "Notas sobre la cuestión nacional en América Latina”, René Zavaleta sostiene que existen países como Bolivia, Perú, Guatemala, Ecuador, Colombia, Venezuela, Paraguay, entre otros, donde el problema nacional no se encuentra resuelto ${ }^{5}$. Las reflexiones sobre este tópico son centrales en su obra, pues precisamente en lo nacionalpopular, reconoce elementos medulares de un proyecto social emancipador.

Zavaleta sostiene que en formaciones sociales abigarradas ${ }^{6}$ la cuestión nacional es un problema incompleto y abierto, agregando que el mismo debe analizarse a partir de la

\footnotetext{
${ }^{5}$ Ya en la década de los setenta del siglo XX, diferentes organizaciones indígenas de Ecuador, Bolivia y Perú, instalaron el debate en torno al problema nacional. Específicamente en el caso boliviano, es relevante la tesis política propuesta por el katarismo en 1983, donde por primera vez se propone la construcción de un "Estado plurinacional". Ver: Albó, Xavier. Pueblos indios en la política. La Paz, CIPCA, 2002.

6 Para Zavaleta la categoría de formación social abigarrada remite a la sobreposición desarticulada de varios modos de producción, de varias concepciones de mundo y de estructuras de autoridad. Esto refiere a la sobreposición desarticulada de diferentes regímenes de propiedad, de diferentes relaciones sociales de producción, de variadas formas de auto-gobierno, etc., todo lo cual, se encuentra subordinado a estructuras coloniales y modernas de dominación. Además, la noción de abigarramiento permite pensar que no sólo
} 
especificidad histórica de cada país. Para el marxista boliviano, la nación refiere a un yo colectivo, a la construcción de una identidad colectiva o, en el marco del capitalismo, a una "entidad histórica formada por hombres jurídicamente libres"7.

Con un marcado énfasis historicista, Zavaleta analizó los procesos históricos latinoamericanos y distinguió tres formas de construcción de lo nacional: Primero, a partir de procesos de homogeneización social mediante el exterminio y el genocidio a poblaciones indígenas. Segundo, a partir de transformaciones territoriales y de cambios en la estructura de la población, a partir de la inculcación de relaciones sociales capitalistas. Y tercero, destruyendo formas de organización previas, pero sin lograr integrar a estas poblaciones a las relaciones sociales capitalistas.

La construcción de lo nacional, en el marco de la configuración de los estados capitalistas latinoamericanos, adquiere mayor profundidad si nos detenemos en las categorías marxistas de subsunción formal y subsunción real, de las cuales podemos señalar dos grandes elementos:

Uno, cuando se desarrolla un proceso de subsunción formal, se disuelven de manera violenta los vínculos de hombres y mujeres con la tierra, con los instrumentos de trabajo y con la comunidad, forzándolos a vender su fuerza de trabajo para sobrevivir. Así, se introducen relaciones de mercantilización de la fuerza de trabajo, es decir, se asalarizan las relaciones de producción, pero no se transforman necesariamente todos los procesos de producción y reproducción social (sus creencias, cultura y formas de vida cotidiana no logran subordinarse del todo a las relaciones sociales capitalistas). Es decir, con la subsunción formal aún no se desorganizan o transforman totalmente las formas de reproducción social no-capitalistas (o comunitarias).

Por el contrario, con la subsunción real se logra el encierro completo de hombres, mujeres y comunidades al capital. Esta implica la transformación de los procesos de producción y reproducción social, del sistema de creencias, de la eliminación de formas de vida comunitaria, de formas de auto-gobierno, entre otras. La subsunción real permite la construcción de la hegemonía y del bloque histórico, puesto que se establecen vínculos compatibles entre estructuras económicas, producción de formas de gobierno y de todos los aspectos de la vida social.

En América Latina, caracterizada por la existencia de numerosas formaciones sociales abigarradas, ha predominado la subsunción formal por sobre la subsunción real, lo que

existen formas multiculturales, sino que también existen formas multisocietales. Ver Tapia, Luis. "Prólogo". En La Autodeterminación de las masas. René Zavaleta, Antología. Bogotá, Siglo del Hombre Editores y CLACSO, 2009.

7 Zavaleta Mercado, René. “Notas sobre la cuestión nacional en América Latina”. En El Estado en América Latina. La Paz, Editorial Los Amigos del Libro, 1981a. p. 46 
permite constatar y re-afirmar la debilidad, inconclusión y apertura de los procesos de construcción de los estados nacionales ${ }^{8}$.

El problema de lo nacional en América Latina es anudado por el marxista boliviano con el problema de la dependencia, estableciendo así un puente complejo entre lo nacional y lo mundial $^{9}$. A partir de esto, y debatiendo con las teorías de la dependencia, Zavaleta reconocerá que no existen historias locales o nacionales que se encuentren incontaminadas de procesos mundiales. Se opone a teorías generales en torno a la dependencia en Latinoamérica; critica la influencia estructuralista de ciertas líneas del debate dependentista; y cuestiona el carácter lineal y homogéneo al momento de analizar las relaciones centro/periferia. La posición zavaletiana enfatizó en lo local, en lo específico. Planteado en sus propias palabras: "En otros términos, cada formación social o país elabora un tipo particular de dependencia. La dependencia por su naturaleza es un hecho particular" 10 .

La preocupación de Zavaleta por comprender la especificidad histórica de lo nacional, por comprender las correlaciones de fuerza, disputas y luchas sociales que se despliegan al interior de cada Estado-Nación, contiene una inquietud política: la de analizar la autodeterminación popular como contra-cara de la dependencia. Planteado en sus propios términos, podemos reconocer que le preocupa definir el "grado de autodeterminación que puede tener una historia nacional, cuáles las condiciones en las que se produce un proceso autodeterminativo"11.

El problema de lo nacional contiene una relevancia estratégica para los procesos revolucionarios. Zavaleta se encuentra pensando en las posibilidades de generar procesos de autodeterminación, precisamente en contextos políticos dictatoriales y de trasnacionalización de la economía. La siguiente cita sintetiza lo que queremos señalar:

La quimera de la abolición del sentido de lo nacional y aún más, el 'agón' de disolución de lo nacional-popular, fracasan frente al sentido innato de la apropiación humana de la historia. Lo nacional sigue siendo el reconocimiento posible dentro de

\footnotetext{
${ }^{8}$ La resistencia aymara y quechua en Bolivia, así como las luchas por el territorio, el bilingüismo y la interculturalidad de las comunidades indígenas en América Latina, son conflictos actuales que, desde la perspectiva zavaletiana, podrían asociase a la apertura e irresolución del problema nacional en la región. Para profundizar en los planteamientos sobre la subsunción formal y real ver: Tapia, Luis. De la forma primordial a América Latina como horizonte epistemológico. La Paz, Editorial CIDES - UMSA, 2013.

${ }^{9}$ Enzo Faletto reparó precisamente en que una de las especificidades del estado latinoamericano es su carácter dependiente y retrasado en lo que refiere al mercado internacional. Obviamente, los estados se enmarcan en una relación mundial centro/periferia. El estado dependiente debía asegurar la "forma de dependencia". Ver Faletto, Enzo. “La especificidad del Estado latinoamericano". En Revista CEPAL N 38: 1989, p. 71.

${ }^{10}$ Zavaleta Mercado, René. "Problemas de la determinación dependiente y la forma primordial". En El Estado en América Latina. La Paz, Editorial Los Amigos del Libro, 1983a. p. 129.

${ }^{11}$ Zavaleta, 1983a, op. cit., p. 126.
} 
los términos de la trasnacionalización. Pero es cierto que una cosa es imprimir el propio carácter a la dependencia y otro erigir una estructura de autodeterminación ${ }^{12}$.

Lo nacional es estratégico a la hora de enfrentar el problema de la dependencia desde proyectos revolucionarios. Lo nacional, en el contexto de sociedades abigarradas como las de América Latina, contiene en su seno un conjunto de formas modernas y no-modernas, comunitarias y populares, de movilización y lucha política contra el dominio capitalista y colonial. Así entonces, lo nacional no podía ser restringido a los proyectos oligárquicos del siglo XIX y de la primera mitad del siglo XX, sino que debía configurarse como bastión de la lucha popular ${ }^{13}$.

\section{Notas sobre teoría del Estado y su especificidad en América Latina}

Para introducirnos a este tercer apartado, recogeremos algunos debates teóricos del Estado desplegados por el marxista boliviano contra las perspectivas estructuralistas e instrumentalistas que tuvieron gran influencia durante la segunda mitad del siglo $\mathrm{XX}$, $\mathrm{y}$ posteriormente, intentaremos acopiar algunos componentes específicos de la problemática estatal en América Latina.

A partir de interrogantes asociadas a la existencia de una teoría marxista del Estado, a la existencia de una teoría general del Estado que permitiera configurar un modelo de regularidad para la superestructura o, a partir de preguntas sobre la pertinencia de la noción de correspondencia entre la base económica y la superestructura, René Zavaleta, irá elaborando importantes contribuciones teóricas en torno al Estado. Conforme a su permanente preocupación por lo local y lo histórico específico, el marxista boliviano valorará las categorías intermedias producidas desde el marxismo, como las de formación económico-social, la de bloque histórico o la de superestructura, en tanto ellas permiten detenerse en la historicidad del Estado. Por el contrario, la categoría de modo de producción capitalista refiere a un modelo de regularidad y a procesos de mundialización de la historia, lo que termina por ser un obstáculo para comprender la complejidad de lo estatal.

En esta misma línea, René Zavaleta reivindicó la noción marxista de autonomía relativa para concebir la especificidad de la superestructura o si se prefiere para reivindicar la autonomía (parcial) de lo político. Desde esta perspectiva, el Estado no puede concebirse ni comprenderse como un ente aislado de la sociedad, pues es interno y externo a ella. Si bien en algunos casos históricos, puede desprenderse de la sociedad civil, o en otros, puede distanciarse ocasionalmente de la misma, resulta completamente erróneo concebirlos como

\footnotetext{
12 Zavaleta, 1983a, op. cit., p. 140.

${ }^{13}$ Ver: Tapia, Luis. "Consideraciones sobre el trabajo teórico de Zavaleta a partir de la obra de Marx" En René Zavaleta Mercado. Pensamiento crítico y marxismo abigarrado. Santiago de Chile, Editorial Quimantú, 2016.
} 
dimensiones separadas o aisladas ${ }^{14}$. Estado y sociedad poseen una relación intermitente. El Estado actúa, produce, interviene en la sociedad civil, y a su vez, el Estado es resultado de la sociedad ${ }^{15}$. Es a partir de esta compleja relación entre Estado y sociedad que Zavaleta reconoce a la noción de autonomía relativa como una de las categorías más potentes producidas desde el marxismo ${ }^{16}$.

En el ensayo titulado "El Estado en América Latina", René Zavaleta debatió con las visiones estructuralistas e instrumentalistas del Estado, puesto que desde su perspectiva intentaban construir un universo de categorías cerradas, puras, separadas y distantes de lo factual. Sus reflexiones son ricas, puesto que dialoga y debate con los teóricos del Estado marxistas más influyentes de la segunda mitad del siglo XX (Louis Althusser, Nicos Poulantzas y Ralph Miliband).

Desde la perspectiva de Zavaleta, los estructuralistas sostenían que no importaba quien fuera el titular del poder del Estado, sino que lo central era comprender el poder en sí, como una relación objetiva que recoge la imposición de la clase dominante y también las conquistas de los sectores subalternos. A partir de esta reflexión, el Estado condensa o cristaliza la lucha social y los conflictos de clase. El Estado no sólo es resultado de la conflictividad social ${ }^{17}$. La preocupación que manifiesta el marxista boliviano con respecto a la lectura estructuralista, es que esta atribuye un carácter estable, fijo, casi inmutable a la hegemonía. Zavaleta sostiene, con Gramsci, que la dominación nunca es estable y que por tanto pensar en victorias totales es un absurdo. Para Zavaleta, las estructuras de poder jamás pueden descontextualizarse, distanciarse de procesos históricos.

Continuando el debate con los estructuralistas, particularmente con Nicos Poulantzas, Zavaleta reconoce, desde Lenin, que el Estado es una síntesis de la sociedad, pero ello no

\footnotetext{
${ }^{14}$ El sociólogo chileno Carlos Ruiz, advierte precisamente sobre la importancia de no detenerse en un análisis superficial de las cosas, pues precisamente desde la perspectiva marxista debemos tratar de centrar nuestros análisis en las relaciones sociales que gestan el mundo de las cosas. Tras la apariencia de las cosas, se encuentra la sociedad, el trabajo humano. Planteado en sus propios términos "la dominación capitalista construye una visión centrada en los objetos y fenómenos de superficie, y oculta el carácter de las relaciones humanas que hacen posible su poder (...). También construye una imagen de las luchas de poder reducida a las instituciones y los procesos jurídico-formales, donde tiene el papel principal, cuando en realidad la fuente constante de su poder político se extiende por toda la sociedad en las formas que impone a las relaciones humanas". Ver Ruiz Encina, Carlos. De nuevo la sociedad. Santiago de Chile, LOM Ediciones / Fundación Nodo XXI, 2015, p. 185.

15 Con respecto a este punto, me parecen complementarios los planteamientos del politólogo argentino Guillermo O’Donnell, quien sostuvo que el Estado es co-constitutivo de la sociedad. Para O’Donnell, el Estado es conceptualizado como parte intrínseca y constitutiva de las relaciones sociales de producción capitalista, es decir, el Estado es garante, no neutral, por cierto, de relaciones sociales de dominación, jugando un papel protagónico en la configuración de la sociedad de clases. Ver O’Donnell, Guillermo. "Apuntes para una teoría del Estado". En Oszlak, Oscar. Teoría de la burocracia estatal. Buenos Aires, Paidós, 1984.

16 Zavaleta Mercado, René. "El Estado en América Latina". En El Estado en América Latina. La Paz, Editorial Los Amigos del Libro, 1983b.

17 Ver Fleury, Sonia. "La naturaleza del Estado capitalista y de las políticas públicas”. En Estado sin ciudadanos, Buenos Aires, Lugar Editorial, 1997.
}




quiere decir que el Estado sea un espejo o reflejo de la sociedad ${ }^{18}$, puesto que si fuera así, el Estado sería un proceso objetivo o una conclusión. Para Zavaleta, la referencia al Estado en términos generales, sin considerar las condiciones históricas específicas, no resuelve el estado de las cosas.

Además, debatiendo con Louis Althusser y su noción de aparatos ideológicos del Estado, Zavaleta señaló que efectivamente existen casos concretos donde los sindicatos, partidos, universidades o escuelas, han funcionado como instituciones cooptadas, leales y sumergidas en la lógica estatal, por tanto, sus funciones pueden leerse como brazos del Estado y sus dirigentes como funcionarios estatales. Ahora bien, por más que esto haya ocurrido, resultaría erróneo o indebido congelar a estas instituciones como aparatos ideológicos del Estado, puesto que las mismas también han actuado, en la historia específica de América Latina, como espacios contrarios al Estado, como escenarios de contrahegemonía ${ }^{19}$.

Finalmente, y ahora debatiendo con las perspectivas instrumentalistas del Estado, Zavaleta sostuvo que: "en su acepción más remota es claro que el Estado es un aparato de una clase o de un bloque para dominar a otro, aunque sea de un modo diferido. En realidad la forma instrumental es una reminiscencia de los momentos primarios del poder" 20 . A partir de lo señalado, Zavaleta reconoce la instrumentalidad del Estado en períodos históricos prolongados asociados a la acumulación originaria, sin embargo, le parece que se deben señalar muchos matices.

Dialogando con Ralph Miliband, Zavaleta reconoce que la instrumentalidad del Estado " $n o$ puede significar la ocupación literal y material del aparato estatal por la burguesía" 21. Para nuestro autor, parece más adecuado referirse a situaciones de instrumentalidad, más que a una visión instrumental del Estado ${ }^{22}$. Dicho énfasis, se encuentra en los procesos históricos concretos.

${ }^{18}$ En un texto referencial de la sociología latinoamericana, Fernando Henrique Cardoso y Enzo Faletto entendieron al Estado como pacto básico de dominación, como relación política de dominación que refleja o sintetiza los intereses de las clases dominantes. Dicha conceptualización fue matizada, señalando que para mantenerse en una situación de dominio, el Estado intenta generalizar sus intereses, es decir, mistifica la parcialidad de sus intereses como si fueran intereses generales. A esto agregaron que los estados implementan políticas que responden al pacto de dominación, pero a su vez, atienden (de manera variable y asimétrica) a las aspiraciones de los grupos dominados. Ver Henrique Cardoso, Fernando y Faletto, Enzo. "Post Scriptum". En Dependencia y desarrollo en América Latina. CEDES. 1975, pp. 167- 213.

${ }^{19}$ Sin ir más lejos, Zavaleta sostiene que el sindicalismo boliviano, desde antes de la Revolución de 1952 , tiene un claro y abierto proyecto anti-estatal, lo que ejemplificaría en términos históricos la hipótesis general y abstracta de los sindicatos como aparatos ideológicos del Estado.

${ }^{20}$ Zavaleta, 1983b, op. cit., p. 175.

${ }^{21}$ Idem

${ }^{22}$ Como bien han señalado algunos politólogos argentinos, el Estado no es garante de una clase determinada sino más bien, de una relación social, y por ende, puede actuar según el caso, en beneficio de los capitalistas o de los/as trabajadores/as. A pesar de esto, podemos afirmar que el Estado posee una complicidad estructural con la producción y reproducción de relaciones sociales capitalistas. Ver O’Donnell, 1984, op. cit.; Ouviña, Hernán. "El Estado: su abordaje desde una perspectiva teórica e histórica". En Sara Lifszyc (comp.) 
Los debates teóricos en torno al Estado desplegados por Zavaleta serán relevantes para configurar su propia visión sobre la especificidad del Estado en América Latina. A continuación, parece importante referirnos al menos a tres componentes de la problemática estatal, a saber: Uno, la construcción de estados nacionales específicos, en tanto emergen en sociedades abigarradas; dos, la configuración de formas primordiales o ecuaciones sociales particulares, entendidas como el conjunto de formas que asume la relación entre Estado y Sociedad Civil; y tres, la existencia de momentos constitutivos o crisis orgánicas, que permiten aproximarnos a la comprensión de nuestra complejidad histórica.

Así entonces, un primer componente que dota de especificidad a los estados nacionales en América Latina es su constitución en el marco de formaciones sociales abigarradas. Como ya señalamos en el apartado anterior, lo abigarrado implica reconocer la superposición de mundos, culturas, memorias, temporalidades e historias diversas. En este sentido, las sociedades latinoamericanas contienen culturas que no han sido ni plenamente integradas ni del todo disueltas. Más bien, son sociedades que han intentado, de manera fallida, subsumir a todos los grupos humanos en un único patrón colonial y capitalista ${ }^{23}$. En este escenario social, se configuran estados aparentes, los cuales intentan imponer una cultura y una lengua oficial; desconocen las formas de organización propias de las comunidades indígenas; niegan las formas locales de autoridad, los ejercicios de deliberación colectiva, entre muchas otras. De esta manera, se configuran esqueletos estatales sin nación, o planteado en jerga gramsciana, dominación sin hegemonía.

En conformidad con lo anterior, René Zavaleta planteó que la construcción de los estados nacionales en América Latina, suponía la desorganización de formas previas de organización política (más o menos comunitarias), intentando la unificación forzada de todas aquellas comunidades y pueblos desarticulados por los procesos de transformación capitalista. Ahora bien, en las formaciones sociales abigarradas, como Bolivia, Perú, Guatemala, Ecuador, etc., perviven múltiples formas de organización política que no han logrado ser desorganizadas y que co-existen con el Estado-Nacional y el poder central.

Lo señalado, se grafica con claridad en la siguiente cita del filósofo boliviano Luis Tapia:

La debilidad de los Estados-Nación en condiciones de abigarramiento se debe a esta diversidad de formas de sociedad y persistencia de sus formas de autogobierno. Esto

Introducción al conocimiento de la Sociedad y el Estado. Buenos Aires, Editorial Gran Aldea, 2003. Por su parte, según el sociólogo chileno Enzo Faletto, el Estado jamás es neutral en los conflictos que se despliegan en la sociedad civil, pero tampoco es la expresión de un solo segmento social como sostienen las teorías instrumentalistas del Estado. Para Faletto, al interior del Estado se expresan las pugnas políticas de la sociedad, por ende si se pretende comprender el carácter estatal, deben analizarse los conflictos sociales. Ver Faletto, 1989, op. cit.

${ }^{23}$ Enzo Faletto también se percata de esta problemática, pero sus reflexiones las articula de otra manera, sosteniendo que existe una flagrante contradicción en los estados latinoamericanos, puesto que en su seno coexiste un Estado moderno, ordenado constitucional, jurídica e institucionalmente, con un complejo entramado de relaciones sociales tradicionales y oligárquicas. Ver Faletto, 1989, op. cit. 
implica que hay varios espacios donde se organiza la vida política según principios y acciones bien diferentes y, obviamente, la participación política principal y orgánica se da en las asambleas de comunidad o red de comunidades de los pueblos indígenas y no así en las instituciones de mediación con el Estado-Nacional ${ }^{24}$.

Así planteado, en sociedades abigarradas como algunos países latinoamericanos, las formas políticas que asume la sociedad civil adquiere en ocasiones la forma de asamblea de comunidades, más que la forma estatal ${ }^{25}$.

La relevancia de estos planteamientos es que por un lado, reparan en la relevancia de las formas de organización política de las comunidades indígenas, permitiendo visibilizar en ellas formas alternativas y contrahegemónicas de concebir la democracia, la participación, la deliberación colectiva y el auto-gobierno; y por otro, porque avanzan en bosquejar reflexiones y discusiones en torno a lo plurinacional de nuestras sociedades y a sus consecuencias políticas en términos legales, institucionales y constitucionales.

Un segundo componente que dota de especificidad al Estado en América Latina según la producción teórico-política de Zavaleta, radica en la relación compleja entre Estado y sociedad civil. Para Zavaleta, dicha relación es trabajada a partir de las categorías de forma primordial o ecuación social, las que dialogan con el concepto gramsciano de bloque histórico. Así entonces, la categoría de forma primordial o ecuación social refiere al grado en que la sociedad existe en el Estado y viceversa, pero también a las formas en que el Estado y la sociedad civil se separan y distancian. "Por razones propias de cada caso, hay ecuaciones en las que la sociedad es más robusta y activa que el Estado, ecuaciones donde el Estado parece preexistir y dominar sobre la sociedad, al menos durante períodos determinados y sistemas donde hay una relación de conformidad o ajuste"26.

La forma primordial tiene un carácter móvil, dinámico, cambiante. El Estado y la sociedad se invaden, se reciben, se interpretan.

La ecuación o bloque tiene entonces elementos verificables de historicidad y azar, no es una estructura predicha. Es una obra de los hombres materialmente determinados, algo que pudo haber sucedido de manera distinta a como sucedió. Como en todo modelo superestructural, podemos obtener algunas series causales o líneas de agregación pero en último término la teoría del Estado, si es algo, es la historia de

\footnotetext{
${ }^{24}$ Tapia, 2013, op. cit., p. 106.

25 Álvaro García Linera (2015), actual vice-presidente de Bolivia, recoge los planteamientos de Zavaleta, y sostiene que la vía democrática para avanzar al socialismo requiere ampliar el pluralismo político, fortaleciendo la democracia representativa, y amplificar los espacios de democracia directa, rebasando los espacios representativos con espacios de democracia comunitaria, de asambleas territoriales, de experiencias sindicales. Cabe agregar que la actual constitución política del Estado de Bolivia, reconoce tres tipos de democracias: representativa, directa y comunitaria.

${ }^{26}$ Zavaleta, op. cit., 177.
} 
cada Estado. Lo que importa, por todo, es el recorrido de los hechos en la edificación de cada Estado ${ }^{27}$.

Con todo esto, se re-afirma lo ya planteado en numerosas ocasiones en este texto, es decir la relevancia analítica, conceptual, teórica y política de analizar la historia concreta, local, nacional, o planteado de otra manera, la especificidad material de cada Estado existente en América Latina ${ }^{28}$.

Un tercer componente de la especificidad del Estado Latinoamericano según Zavaleta, se debe buscar en el momento constitutivo, concepto que refiere a "un momento en que las cosas comienzan a ser lo que son" 29 . En otros términos, es la causa remota de la realidad actual. Dicha categoría se asocia a la noción de gramsciana de crisis orgánica y a la noción marxiana de acumulación originaria. Explicado por Luis Tapia, "un momento constitutivo es aquel donde algo adquiere la forma que va a tener la vida social por un buen tiempo hacia adelante, es el momento en que se articula algo, así como un programa de vida social o de un orden social que va a funcionar como gran determinación" ${ }^{\prime 30}$.

Según Zavaleta, en formaciones sociales abigarradas como la sociedad boliviana y numerosas sociedades Latinoamericana, los momentos constitutivos $^{31}$ se perfilan como períodos relevantes para comprender la complejidad social, puesto que permiten visibilizar lo heterogéneo de la realidad, posibilitando así, la ampliación del conocimiento social. De hecho, numerosos autores sostienen que para el marxista boliviano los momentos constitutivos o las crisis orgánicas se configuran como un verdadero método de conocimiento, en tanto permiten visibilizar las fallas, lo extraordinario, lo desgarrado y lo complejo de la realidad social ${ }^{32}$.

A partir de dicho concepto, podemos sostener que los procesos de formación nacional remiten a momentos constitutivos diferenciales. Es decir, los procesos de descampesinización, de separación originaria de las comunidades y sus medios de producción, la asignación de un estatuto de libertad jurídica a los seres humanos desvinculados de sus tierras, la destrucción de aldeas y comunidades, etc., son procesos que se vivieron de diferentes maneras en América Latina.

\footnotetext{
27 Zavaleta, op. cit., p. 180.

${ }^{28}$ En completa sintonía con lo planteado por el marxista boliviano, el sociólogo chileno Enzo Faletto (1989), sostuvo en reiteradas ocasiones que la especificidad del Estado en América Latina se expresaba según las particularidades económicas y sociales del capitalismo en cada país.

${ }^{29}$ Zavaleta, op. cit., p. 180.

30 Tapia, Luis. "Prólogo". En La Autodeterminación de las masas. René Zavaleta, Antología. Bogotá, Siglo del Hombre Editores y CLACSO, 2009. p. 21.

${ }^{31}$ En el caso boliviano, la revolución de 1952, también puede comprenderse como un momento constitutivo, en tanto es relevante en la conformación del movimiento obrero y del nacionalismo revolucionario. Dicha experiencia histórica permite reconocer la energía de las clases nacionales (obreros, campesinos, indígenas, sectores medios) y oponerse a las tesis darwinistas que sostenían el carácter enfermo del pueblo boliviano.

${ }^{32}$ Ver García Yapur, Fernando. "Nación y hegemonía incompleta en Zavaleta Mercado". En Revista RECIAL N9, Universidad Nacional de Córdoba, Argentina. 2016.
} 


\section{Dictadura, Democracia y Autodeterminación de las masas}

En el texto "Notas sobre fascismo, dictadura y coyuntura de disolución", Zavaleta, preocupado por los golpes de Estado y las dictaduras militares en la región, afirmó que la forma normal del Estado capitalista es la democracia burguesa, por tanto concibe y conceptualiza las dictaduras como "formas de emergencia o excepción del Estado capitalista" "33. La dictadura no sería la forma más favorable de desarrollo del capitalismo, aunque si le permite a los sectores dominantes establecer una re-organización de clase. Las dictaduras, como formas coyunturales o anómalas del capitalismo, pueden expresar la incapacidad de las clases dominantes de racionalizar una relación de poder, pueden graficar su falta de unidad como bloque hegemónico o pueden visualizarse como su última alternativa para salvar un modelo económico ${ }^{34}$ (Salamanca, 2015).

Las dictaduras latinoamericanas no pueden calificarse estrictamente como fascistas ${ }^{35}$, pero muchas de ellas si se encuentran inspiradas por un proyecto fascista, pues impulsan las lógicas del capital monopólico, del imperialismo y del desbaratamiento de la clase obrera. Ahora bien, para Zavaleta en América Latina "han sido proyectos que no han obtenido legitimación ideológica a nivel de las masas" ${ }^{\prime 3}$. Este planteamiento, probablemente haya sido correcto para el período de producción del texto de Zavaleta, sin embargo, desde nuestra perspectiva (y según los resultados del plebiscito de 1988), la dictadura militar en Chile, si logró amplios niveles de legitimidad social.

Zavaleta para analizar las dictaduras latinoamericanas, se preocupó de la política imperialista de los EE.UU. y en ese contexto, logró constatar que el ciclo de golpes de Estado en América Latina se desarrolló a partir de los flujos de EE.UU. hacia la periferia (determinación exógena de la forma política) y de los procesos históricos nacionales (determinación endógena).

A lo planteado, se puede agregar que los procesos autoritarios pueden ser analizados a partir de dos ciclos: Un primer ciclo, caracterizado por la disolución de las experiencias nacional-populares por vía de golpes de Estado; y un segundo ciclo, donde se constituyen

\footnotetext{
33 Zavaleta Mercado, René. "Notas sobre fascismo, dictadura y coyuntura de disolución". En El Estado en América Latina. La Paz, Editorial Los Amigos del Libro, 1979. p. 5.

${ }^{34}$ Ver Salamanca, Katherine. "Violencia política y Estado. Lectura de René Zavaleta Mercado sobre política autoritaria en América Latina”. En Revista Interdisciplinaria de Ciencias Sociales N¹, 2015, pp. 9 - 22.

${ }^{35}$ Para Zavaleta, resulta erróneo considerar que las dictaduras latinoamericanas instaladas en el poder desde la década del sesenta sean regímenes fascistas. El fascismo europeo se caracterizaría al menos por tres elementos: Uno, la configuración de un movimiento de masas; dos, la construcción de un proyecto irracionalista; y tres, la conformación de una estructura fascista de poder (Estado Totalitario). Desde la perspectiva del sociólogo y periodista boliviano, estas sumatoria de elementos no se encuentran presentes en todas las dictaduras de la región. De hecho, en varios países ni siquiera desarrollaron procesos refundacionales, es decir, no lograron construir autoritariamente la sociedad, sometiendo la sociedad civil al poder del Estado.

${ }^{36}$ Zavaleta, op. cit., p. 16.
} 
regímenes autoritarios. Reconociendo estos elementos, Zavaleta sostuvo que el imperialismo norteamericano intentó imponer un modelo caracterizado al menos por:

a. Reorganizar verticalmente la sociedad civil, reemplazando formas organizativas por formas corporativas. Se preocupa de reconstruir la gobernabilidad acabando con el desborde social ${ }^{37}$

b. Se promueve la trasnacionalización del acto productivo. Se asume una estrategia económica centrada en la inserción al sistema mundial ${ }^{38}$;

c. Se promueve una ideología oficial, asociada a la Doctrina de Seguridad Nacional, lo que no es otra cosa que una cara político-militar de la teoría de la ingobernabilidad de la democracia; y

d. Se generaliza el terror como movimiento de reconstitución ideológica.

Ahora bien, y pasando a la supuesta contra-cara de las dictaduras, Zavaleta, afirmándose en Lenin, sostuvo que, en el capitalismo, la democracia es la forma aparente o travestida de la dictadura. Planteado en sus términos: "Debe decirse, por otra parte, que, puesto que todo Estado es en último término una dictadura, la democracia burguesa es, en consecuencia, el grado de democracia necesario para que la dictadura de la burguesía exista y también el grado de democracia que puede admitir la burguesía sin perder su dictadura"39.

A lo señalado, Zavaleta agrega que, en el capitalismo, el proletariado es parte constitutiva de la sociedad burguesa, por tanto, no puede rechazar la democracia burguesa. Según su perspectiva, la democracia burguesa es un factor favorable al proletariado, aunque evidentemente no se trata de divinizarla ni de concebirla como un fin, sino como un medio que permite romper el consenso, la hegemonía o la mediación de la burguesía. La valoración de la democracia radica en que la misma expresa la dominación de la burguesía, pero a su vez, expresa la correlación de fuerzas entre las clases sociales encerradas en la dominación burguesa. Para Zavaleta, es a partir de la democracia que el proletariado debería romper la alianza de la burguesía con los sectores medios y la clase obrera de

\footnotetext{
${ }^{37}$ Enzo Faletto (1989), debate con aquellas concepciones que refieren a la ingobernabilidad que genera la democracia al dar cabida a demandas sociales y a la participación popular. El problema debería invertirse, y para ello sirve señalar que no es el desborde reivindicativo o la democratización social el problema de la democracia en los estados latinoamericanos, sino la rigidez institucional, jurídica y constitucional para atender a las demandas sociales.

${ }^{38}$ En diálogo con lo planteado, los sociólogos Fernando Henrique Cardoso y Enzo Faletto sostuvieron que las dictaduras Latinoamericanas configuraron Estados autoritarios, burocráticos y represivos, lo que se expresó en el incremento de las burocracias militares y en la restricción de los sistemas democráticos, y además, establecieron alianzas con las empresas extranjeras de carácter trasnacional. Los sociólogos referenciados sintetizan con claridad este último elemento: "Lo que es característico del capitalismo dependiente en la fase de industrialización de la periferia bajo el impulso del capitalismo oligopólico internacional es el desarrollo de una forma estatal basada en la alianza entre empresa multinacional, empresariado estatal y burguesía local a través de lo cual estos sectores generan el dominio sobre el resto de la sociedad". Ver Henrique Cardoso y Faletto, op.cit., p. 295.

39 Zavaleta Mercado, René. "Notas sobre fascismo, dictadura y coyuntura de disolución”. En El Estado en América Latina. La Paz, Editorial Los Amigos del Libro, 1979. p. 7.
} 
conciencia no proletaria, movilizando, en función de un nuevo proyecto histórico nacional, a los sectores sociales que han naturalizado el capitalismo como único posible.

A partir de lo planteado, el proletariado debería ser capaz de configurar un proyecto estatal nacional (no sólo para sí mismo), pues de lo contrario el escenario político corre el riesgo de devenir en guerras civiles o en golpes de estado militares de sello autoritario y conservador. Con estos planteamientos, René Zavaleta analiza por defecto las dictaduras latinoamericanas como el resultado histórico de errores estratégicos en el seno de la clase y de los partidos de izquierda.

Posicionado críticamente con respecto a la democracia burguesa, Zavaleta señaló que la misma contiene en su seno una contradicción fundamental. Lo que se expresa en el siguiente texto: "La libertad de la democratización social contiene a la vez la grandeza del capitalismo, capaz de generar masas de individuos nacionales e identificados; y la perdición del capitalismo, porque la socialización de la producción es la preparación de la socialización del poder"

Avanzando en la superación de la democracia representativa, concebida como el requisito de la existencia de la sociedad burguesa y del capitalismo, René Zavaleta propone la adscripción a una concepción de democracia entendida como autodeterminación de las masas. En esta categoría, se comprende la autodeterminación como un acto revolucionario (y no necesariamente como un acto legal), que emana de una voluntad de poder, que generalmente se expresa de manera creativa y espontánea. Y la masa se asocia a las fuerzas productivas de una nación o, planteado en otros términos, a la Sociedad Civil en acción.

La democracia, entendida como autodeterminación de las masas, le permite a nuestro autor avanzar en relevantes proyecciones políticas, en tanto logra articular democracia y revolución, categorías extraviadas y divorciadas para muchos referentes intelectuales de izquierda durante la segunda mitad del siglo XX. Para el marxista boliviano, "La democracia entendida como autodeterminación de las masas viene a ser el desiderátum de este discurso. La historia de las masas es siempre una historia que se hace contra el Estado, de suerte que aquí hablamos de estructuras de rebelión y no de formas de pertenecimiento". Y nuestro autor continúa "Se puede decir que aquí se reemplaza la democracia para la clase dominante por la democracia para sí misma"41.

Ahora bien, Zavaleta finaliza sus reflexiones en torno a la autodeterminación de las masas, advirtiéndonos que la misma puede ser portadora de tradiciones democráticas (progresistas, revolucionarias) y de tradiciones no-democráticas (conservadoras, autoritarias, fascistas). Puede ser racional o irracional, puede reproducir y fortalecer la servidumbre y el antisemitismo o puede promover procesos igualitarios y emancipatorios. Su horizonte

${ }^{40}$ Zavaleta Mercado, René. “Cuatro conceptos de la Democracia”. En El Estado en América Latina. La Paz, Editorial Los Amigos del Libro, 1981b. p. 69.

${ }^{41}$ Zavaleta, op. cit., p. 82. 
político se encuentra abierto a las correlaciones de fuerza y las expresiones de las luchas sociales, lo que nos pone en alerta de la relevancia de la arena política, social, cultural y económica, como espacios de disputa por la sociedad que queremos y necesitamos.

\section{Bibliografía referenciada}

Albó, Xavier. Pueblos indios en la política. La Paz, CIPCA, 2002.

Concheiro, Elvira. "El análisis concreto de situaciones concretas: Lenin en la obra de René Zavaleta". En René Zavaleta Mercado. Pensamiento crítico y marxismo abigarrado. Santiago de Chile, Editorial Quimantú, 2016.

Faletto, Enzo. "La especificidad del Estado latinoamericano". En Revista CEPAL N 38: 1989, pp. 161-200.

Fleury, Sonia. "La naturaleza del Estado capitalista y de las políticas públicas". En Estado sin ciudadanos, Buenos Aires, Lugar Editorial, 1997.

García Linera, Álvaro. Comunidad, Socialismo y Estado Plurinacional. Santiago de Chile, Ediciones y Publicaciones El Buen Aire, 2015.

García Yapur, Fernando. "Nación y hegemonía incompleta en Zavaleta Mercado". En Revista RECIAL N9, Universidad Nacional de Córdoba, Argentina. 2016.

Guiller, Diego. "El Mariátegui de Zavaleta. Entre Marx y el racionalismo revolucionario". En René Zavaleta Mercado. Pensamiento crítico y marxismo abigarrado. Santiago de Chile, Editorial Quimantú, 2016.

Henrique Cardoso, Fernando y Faletto, Enzo. "Post Scriptum". En Dependencia y desarrollo en América Latina. CEDES. 1975, pp. 167- 213.

Lazarte, Jorge. "Presentación”. En El Estado en América Latina. Cochabamba, Editorial Los Amigos del Libro, 1990.

O’Donnell, Guillermo. “Apuntes para una teoría del Estado”. En Oszlak, Oscar (comp.): Teoría de la burocracia estatal. Buenos Aires, Paidós, 1984.

Oliver, Lucio. "René Zavaleta: La teoría en situaciones de doble poder". En René Zavaleta Mercado. Pensamiento crítico y marxismo abigarrado. Santiago de Chile, Editorial Quimantú, 2016.

Ortega, Jaime. "Horizonte (s) de visibilidad: Sujeto y autoconocimiento. Lúcaks y Zavaleta en la construcción epistemológica del marxismo". En René Zavaleta Mercado. Pensamiento crítico y marxismo abigarrado. Santiago de Chile, Editorial Quimantú, 2016. 
Ouviña, Hernán. "El Estado: su abordaje desde una perspectiva teórica e histórica". En Sara Lifszyc (comp.) Introducción al conocimiento de la Sociedad y el Estado. Buenos Aires, Editorial Gran Aldea, 2003.

Ouviña, Hernán. "Traducción y nacionalización del marxismo en América Latina. Un acercamiento político de René Zavaleta”. En Revista OSAL N²8, Buenos Aires. 2010, pp. 193 - 207.

Ouviña, Hernán. "René Zavaleta, frecuentador de Gramsci". En René Zavaleta Mercado. Pensamiento crítico y marxismo abigarrado. Santiago de Chile, Editorial Quimantú, 2016.

Ruiz Encina, Carlos. De nuevo la sociedad. Santiago de Chile, LOM Ediciones / Fundación Nodo XXI, 2015.

Salamanca, Katherine. "Violencia política y Estado. Lectura de René Zavaleta Mercado sobre política autoritaria en América Latina”. En Revista Interdisciplinaria de Ciencias Sociales $\mathrm{N}^{\circ} 1$, 2015, pp. $9-22$.

Tapia, Luis. "Prólogo". En La Autodeterminación de las masas. René Zavaleta, Antología. Bogotá, Siglo del Hombre Editores y CLACSO, 2009.

Tapia, Luis. De la forma primordial a América Latina como horizonte epistemológico. La Paz, Editorial CIDES - UMSA, 2013.

Tapia, Luis. "Consideraciones sobre el trabajo teórico de Zavaleta a partir de la obra de Marx" En René Zavaleta Mercado. Pensamiento crítico y marxismo abigarrado. Santiago de Chile, Editorial Quimantú, 2016.

Viaña, Jorge. "Zavaleta, Reinaga y la lucha por la construcción de prácticas y pensamiento emancipativo en el actual ciclo estatal boliviano". En René Zavaleta Mercado. Pensamiento crítico y marxismo abigarrado. Santiago de Chile, Editorial Quimantú, 2016.

Zavaleta Mercado, René. "Notas sobre fascismo, dictadura y coyuntura de disolución”. En El Estado en América Latina. La Paz, Editorial Los Amigos del Libro, 1979.

Zavaleta Mercado, René. "Notas sobre la cuestión nacional en América Latina". En El Estado en América Latina. La Paz, Editorial Los Amigos del Libro, 1981a.

Zavaleta Mercado, René. "Cuatro conceptos de la Democracia". En El Estado en América Latina. La Paz, Editorial Los Amigos del Libro, 1981b.

Zavaleta Mercado, René. "Problemas de la determinación dependiente y la forma primordial". En El Estado en América Latina. La Paz, Editorial Los Amigos del Libro, 1983a.

Zavaleta Mercado, René. "El Estado en América Latina”. En El Estado en América Latina. La Paz, Editorial Los Amigos del Libro, 1983b.

Zavaleta Mercado, René. "Ni piedra filosofal ni Summa Feliz". En El Estado en América Latina. La Paz, Editorial Los Amigos del Libro, 1983c. 